\title{
Data on Evaluation of the Corrosion Inhibition Effect of L-alpha-aminoisocaproate on High Carbon Steel Corrosion in Dilute Acid Media
}

\author{
Roland Tolulope LOTO $^{1 *}$, Cleophas Akintoye LOTO $^{1,2}$ \\ ${ }^{1}$ Department of Mechanical Engineering, Covenant University, KM 10 Idiroko Road, Ota, Ogun State, Nigeria \\ ${ }^{2}$ Department of Chemical, Metallurgical and Materials Engineering, Tshwane University of Technology, Pretoria, South \\ Africa \\ crossref http://dx.doi.org/10.5755/j01.ms.25.4.21347
}

Received 29 July 2018; accepted 03 October 2018

\begin{abstract}
Corrosion inhibition performance of 1-alpha-aminoisocaproate on high carbon steel in $1 \mathrm{M} \mathrm{HCl}$ solution has been studied by weight loss measurement, open circuit potential measurement, optical microscopy and ATF-FTIR spectral analysis. The results showed the inhibition performance of l-alpha-aminoisocaproate is time dependent attaining an optimal value of $85.88 \%$ at $5.63 \%$ l-alpha-aminoisocaproate concentration (highest concentration) after $288 \mathrm{~h}$ of exposure. The corrosion potential plots of the high carbon steel at $0.91 \%$ (lowest concentration) and $5.63 \%$ 1-alpha-aminoisocaproate concentration were more electropositive than the plots at $0 \%$ l-alpha-aminoisocaproate concentration due to the effective inhibition performance of l-alpha-aminoisocaproate in counteracting the oxidation of the carbon steel in the presence of chloride anions. Identified functional groups of alcohols, phenols, primary and secondary amines and amides, carboxylic acids, alkynes, aromatics, alkenes and alkanes consisting of $\mathrm{O}-\mathrm{H}$ stretch, free hydroxyl, $\mathrm{H}-$ bonded, $\mathrm{N}-\mathrm{H}$ stretch, $-\mathrm{C}$ (triple bond) $\mathrm{C}-\mathrm{H}$ : $\mathrm{C}-\mathrm{H}$ stretch, $\mathrm{C}-\mathrm{H}$ stretch and $=\mathrm{C}-\mathrm{H}$ stretch bonds where responsible for the corrosion inhibition. The optical morphology of the carbon steel after $7200 \mathrm{~s}$ of exposure in the acid solution without 1-alpha-aminoisocaproate was severely corroded in contrast to the morphology of the steel in the presence of 1-alpha-aminoisocaproate which underwent minor deterioration due to the time dependent action of the inhibitor.
\end{abstract}

Keywords: corrosion, inhibition, adsorption, steel.

\section{INTRODUCTION}

Carbon steels are extensively used as construction materials in most industries due to their relatively low cost and excellent mechanical properties [1]. However, they are susceptible to corrosion in aqueous acid environments containing electroactive anions such as chlorides, sulphates, thiosulphates etc. Acidic conditions are prevalent in industrial processes resulting in extensive corrosion damage equipment, structures and pipeline systems made of carbon steels [2-4]. The high cost of corrosion impacts negatively on the revenues of industries due to the need for maintenance, replacement of corroded parts and corrosion control methods. affects numerous industries [5]. In addition to the high cost, environmental and health impact of corrosion are worthy of note especially risks associated sudden breakdown and collapse of structures resulting leaks and hazardous exposure to dangerous chemicals. Corrosion inhibition of carbon steels is the safest, economical and most important method for the sustainability of carbon steels during application. Other methods used for corrosion protection include cathodic protection, anodizing, galvanizing, anodic protection, paint coating, electroplating etc.

Corrosion inhibitors of inorganic origin such as those containing phosphates, chromates, and other heavy metals have been proven to be effective on carbon steels. However, their toxicity and problems emanating from safe disposal have resulted in their outright ban by regulatory authorities
[6-14]. In recent years non-polluting green chemical compounds have been studied for their corrosion inhibition properties. In view of the above this research aims to evaluate the corrosion inhibition performance of L-alphaaminoisocaproate, an alpha amino acid on high carbon steel in dilute hydrochloric acid.

\section{EXPERIMENTAL METHODS}

High carbon steel (HCS) obtained commercially has a nominal (wt.\%) composition shown in Table 1 (from energy dispersive spectrometer analysis at the Materials Characterization Laboratory, Covenant University). The HCS specimens were grinded with silicon carbide papers (80, 320, 600, 800 and 1000 grit) after machining before being cleansed with deionized water and acetone and kept in a desiccator for weight loss and open circuit potential measurement. L-alpha-aminoisocaproate (LAA) obtained from Sigma Aldrich, USA is a white powdery solid with a molar mass of $131.17 \mathrm{~g} / \mathrm{mol} .200 \mathrm{~mL}$ of $1 \mathrm{M} \mathrm{HCl} / 0.91 \%$, $1.88 \%, 2.81 \%, 3.75 \%, 4.69 \%$ and $5.63 \%$ LAA was prepared from analar grade of $\mathrm{HCl}$ acid (37\%) with deionized water.

Table 1. Nominal composition (wt.\%) of HCS

\begin{tabular}{|l|c|c|c|c|c|c|c|c|c|}
\hline Element symbol & $\mathrm{Cu}$ & $\mathrm{Si}$ & $\mathrm{Cr}$ & $\mathrm{Mn}$ & $\mathrm{P}$ & $\mathrm{S}$ & $\mathrm{C}$ & $\mathrm{Mo}$ & $\mathrm{Fe}$ \\
\hline \% Comp. (HCS) & - & 0.3 & - & 0.8 & 0.04 & 0.05 & 0.56 & - & 98.25 \\
\hline
\end{tabular}

\footnotetext{
* Corresponding author. Tel.: +234-8084283392;

E-mail address: tolu.loto@gmail.com (R.T. Luoto)
} 
LAA/1M HCl solution (before and after the corrosion test) were exposed to specific range of infrared ray beams from Bruker Alpha FTIR spectrometer at wavelength range of 375 to $7500 \mathrm{~cm}^{-1}$ and resolution of $0.9 \mathrm{~cm}^{-1}$. The transmittance and reflectance of the infrared beams at various frequencies were decoded and transformed into an FTIR absorption plot consisting of spectra peaks. The spectral pattern was evaluated and equated with FTIR absorption Table to identify the functional groups responsible for corrosion inhibition. Weighed HCS coupons separately immersed in $200 \mathrm{~mL}$ of the dilute acid test solution for $288 \mathrm{~h}$ at $30{ }^{\circ} \mathrm{C}$ were weighed at $24 \mathrm{~h}$ interval according to ASTM G31-72. Corrosion rate $\left(C_{\mathrm{R}}\right)$ is determined as follows as:

$C_{\mathrm{R}}=\left[\frac{87.6 \omega}{D A t}\right]$

where $\omega$ is the weight loss in $\mathrm{mg}, D$ is the density in $\mathrm{g} / \mathrm{cm}^{3}$, $A$ is the total surface area of the coupon in $\mathrm{cm}^{2}$ and 87.6 is a constant for corrosion rate determination in $\mathrm{mm} / \mathrm{y}$. $t$ is the time in $\mathrm{h}$.

Inhibition efficiency $(\eta)$ was determined from the equation below:

$\eta=\left[\frac{\omega_{1}-\omega_{2}}{\omega_{1}}\right] \times 100$,

where $\omega_{1}$ and $\omega_{2}$ are the mass loss at specific LAA concentrations. Open circuit potential measurement (OCP) was performed at $0.2 \mathrm{~V} / \mathrm{s}$ step potential for $7200 \mathrm{~s}$ to study the active-passive behaviour of HCS at rest potentials in the electrolyte solution. Optical micrographs of corroded and inhibited HCS morphology were analysed after OCP with Omax trinocular metallurgical microscope using ToupCam software for analysis. IR absorption Table to identify the functional groups responsible for corrosion inhibition.

\section{RESULTS AND DISCUSSION}

\subsection{Weight-loss measurement}

Experimental data for weight-loss (WL) and corrosion rate (CR) of HCS, and LAA inhibition efficiency (INF) obtained in $1 \mathrm{M} \mathrm{HCl}$ solution for $288 \mathrm{~h}$ of exposure are shown in Table 2 - Table 4.

Table 2. Weight loss data for HCS obtained during $288 \mathrm{~h}$ of exposure in $1 \mathrm{M} \mathrm{HCl}$ media at $0 \%-5.63 \% \mathrm{LAA}$

\begin{tabular}{|l|l|l|l|l|l|l|l|}
\hline $\begin{array}{c}\text { LAA } \\
\text { Exp. } \\
\text { Exc. } \\
\text { time, h }\end{array}$ & $0 \%$ & $0.91 \%$ & $1.88 \%$ & $2.81 \%$ & $3.75 \%$ & $4.69 \%$ & $5.63 \%$ \\
\hline 24 & 0.130 & 0.114 & 0.112 & 0.076 & 0.085 & 0.090 & 0.064 \\
\hline 48 & 0.228 & 0.166 & 0.169 & 0.120 & 0.127 & 0.123 & 0.102 \\
\hline 72 & 0.309 & 0.194 & 0.199 & 0.118 & 0.146 & 0.140 & 0.121 \\
\hline 96 & 0.448 & 0.228 & 0.241 & 0.154 & 0.165 & 0.155 & 0.137 \\
\hline 120 & 0.599 & 0.266 & 0.280 & 0.172 & 0.182 & 0.168 & 0.155 \\
\hline 144 & 0.792 & 0.312 & 0.329 & 0.192 & 0.201 & 0.182 & 0.174 \\
\hline 168 & 0.906 & 0.336 & 0.343 & 0.205 & 0.213 & 0.190 & 0.182 \\
\hline 192 & 1.059 & 0.372 & 0.365 & 0.221 & 0.228 & 0.203 & 0.194 \\
\hline 216 & 1.224 & 0.395 & 0.382 & 0.238 & 0.245 & 0.216 & 0.206 \\
\hline 240 & 1.366 & 0.416 & 0.399 & 0.253 & 0.259 & 0.227 & 0.217 \\
\hline 264 & 1.557 & 0.448 & 0.416 & 0.278 & 0.278 & 0.246 & 0.233 \\
\hline 288 & 1.703 & 0.471 & 0.424 & 0.293 & 0.288 & 0.255 & 0.240 \\
\hline
\end{tabular}

The corrosion rate of HCS at $0 \%$ LAA concentration (Table 3) decreased for the first $72 \mathrm{~h}$ of exposure to $0.0081 \mathrm{~mm} / \mathrm{y}$ before increasing progressively to $0.0111 \mathrm{~mm} / \mathrm{y}$ at $264 \mathrm{~h}$. Within this time frame the weight loss of HCS (Table 2) increased significantly due to severe anodic dissolution and deterioration of the surface morphology of HCS.

Table 3. Calculated data for HCS corrosion rate obtained during $288 \mathrm{~h}$ of exposure in $1 \mathrm{M} \mathrm{HCl}$ media at $0 \%-5.63 \%$ LAA

\begin{tabular}{|l|c|c|c|c|c|c|c|}
\hline $\begin{array}{r}\text { LAA } \\
\text { conc. } \\
\text { Exp. } \\
\text { time, } \mathrm{h}\end{array}$ & $0 \%$ & $0.91 \%$ & $1.88 \%$ & $2.81 \%$ & $3.75 \%$ & $4.69 \%$ & 5.63 \\
\hline 24 & 0.0102 & 0.0089 & 0.0088 & 0.0060 & 0.0067 & 0.0070 & 0.0050 \\
\hline 48 & 0.0089 & 0.0065 & 0.0066 & 0.0047 & 0.005 & 0.0048 & 0.0040 \\
\hline 72 & 0.0081 & 0.0050 & 0.0052 & 0.0031 & 0.0038 & 0.0037 & 0.0032 \\
\hline 96 & 0.0088 & 0.0045 & 0.0047 & 0.0030 & 0.0032 & 0.0030 & 0.0027 \\
\hline 120 & 0.0094 & 0.0042 & 0.0044 & 0.0027 & 0.0029 & 0.0026 & 0.0024 \\
\hline 144 & 0.0103 & 0.0041 & 0.0043 & 0.0025 & 0.0026 & 0.0024 & 0.0023 \\
\hline 168 & 0.0101 & 0.0038 & 0.0038 & 0.0023 & 0.0024 & 0.0021 & 0.0020 \\
\hline 192 & 0.0104 & 0.0036 & 0.0036 & 0.0022 & 0.0022 & 0.0020 & 0.0019 \\
\hline 216 & 0.0106 & 0.0034 & 0.0033 & 0.0021 & 0.0021 & 0.0019 & 0.0018 \\
\hline 240 & 0.0107 & 0.0033 & 0.0031 & 0.0020 & 0.0020 & 0.0018 & 0.0017 \\
\hline 264 & 0.0111 & 0.0032 & 0.003 & 0.0020 & 0.0020 & 0.0018 & 0.0017 \\
\hline 288 & 0.0111 & 0.0031 & 0.0028 & 0.0019 & 0.0019 & 0.0017 & 0.0016 \\
\hline
\end{tabular}

The deterioration leading to weight loss (0\% LAA concentration) continued till the end of the exposure period because of the electrochemical action of chloride anions, due to the disassociation of $\mathrm{HCl}$ in $\mathrm{H}_{2} \mathrm{O}$ with respect to equation:

$\mathrm{HCl}_{(\mathrm{aq})}+\mathrm{H}_{2} \mathrm{O}_{(\mathrm{l})} \rightarrow \mathrm{H}_{3} \mathrm{O}_{(\mathrm{aq})}^{+}+\mathrm{Cl}_{(\mathrm{aq})}^{-}$

The anions react with HCS resulting in rapid surface oxidation of HCS:

$\mathrm{Fe}_{(\mathrm{s})}+2 \mathrm{HCl}_{(\mathrm{aq})} \rightarrow \mathrm{FeCl}_{2(\mathrm{aq})}+\mathrm{H}_{2(\mathrm{~g})}$.

Table 4. Calculated data for LAA inhibition efficiency obtained during $288 \mathrm{~h}$ of exposure in $1 \mathrm{M} \mathrm{HCl}$ media at $0 \%-5.63 \%$ LAA

\begin{tabular}{|l|l|l|l|l|l|l|}
\hline $\begin{array}{r}\text { LAA } \\
\text { conc. }\end{array}$ & $0.91 \%$ & $1.88 \%$ & $2.81 \%$ & $3.75 \%$ & $4.69 \%$ & $5.63 \%$ \\
\hline $\begin{array}{l}\text { Exp. } \\
\text { time, } \mathrm{h}\end{array}$ & & & & & & \\
\hline 24 & 12.43 & 14.04 & 41.52 & 34.77 & 30.93 & 51.19 \\
\hline 48 & 27.36 & 25.87 & 47.39 & 44.19 & 46.30 & 55.24 \\
\hline 72 & 37.42 & 35.58 & 61.77 & 52.78 & 54.56 & 60.71 \\
\hline 96 & 48.98 & 46.17 & 65.62 & 63.21 & 65.40 & 69.38 \\
\hline 120 & 55.51 & 53.24 & 71.33 & 69.52 & 71.94 & 74.06 \\
\hline 144 & 60.56 & 58.41 & 75.71 & 74.60 & 77.02 & 78.08 \\
\hline 168 & 62.92 & 62.11 & 77.39 & 76.48 & 79.03 & 79.90 \\
\hline 192 & 64.92 & 65.59 & 79.16 & 78.48 & 80.84 & 81.72 \\
\hline 216 & 67.73 & 68.83 & 80.55 & 80.03 & 82.39 & 83.16 \\
\hline 240 & 69.58 & 70.81 & 81.45 & 81.01 & 83.36 & 84.15 \\
\hline 264 & 71.19 & 73.25 & 82.14 & 82.16 & 84.19 & 85.01 \\
\hline 288 & 72.35 & 75.10 & 82.82 & 83.09 & 85.02 & 85.88 \\
\hline
\end{tabular}

Due to lack of passivation characteristics on the surface of HCS, continuous deterioration and oxide formation result in the formation of pores and channels within the oxide layer which further aggravates the corrosion HCS. After $240 \mathrm{~h}$ the increase in corrosion rate stalled at $0.0111 \mathrm{~mm} / \mathrm{y}$ due to weakening of the corrosive test solution. At $0.91 \%-5.63 \%$ LAA concentration, HCS corrosion rate reduced 
significantly with respect to LAA concentration from the onset of the exposure hours ( $24 \mathrm{~h}$ ) to $288 \mathrm{~h}$ due to the electrochemical action of protonated LAA molecules acidinhibitor solution which effectively suppressed the redox reactions on HCS surface. LAA inhibition efficiency values (Table 4) tends to be more time dependent than concentration dependence, as its inhibition efficiency values increase with exposure time within the limits of the concentrations studied to peak at efficiency values between $72.35 \%$ and $85.88 \%(0.91 \%$ and $5.563 \%$ LAA $)$ at $288 \mathrm{~h}$. LAA attained $70 \%$ inhibition efficiency between $96-120 \mathrm{~h}$ for $2.81 \%$ to $5.63 \%$ LAA concentration. At $0.91 \%$ and $1.88 \%$ LAA concentration, LAA attained $70 \%$ at about efficiency at about $240 \mathrm{~h}$.

\subsection{Open circuit potential measurement and optical microscopy}

Variation of open circuit corrosion potentials plots of HCS at $0 \%, 0.91 \%$ and $5.63 \%$ LAA concentration versus exposure time for $7200 \mathrm{~s}$ are shown in Fig. 1.

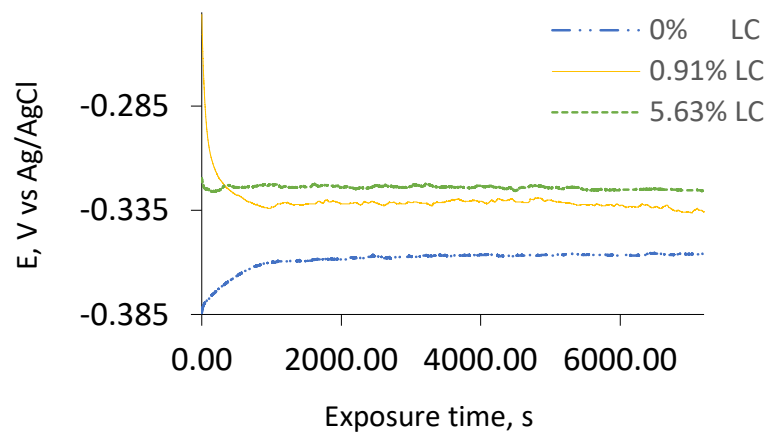

Fig. 1. Variation of open circuit corrosion potential of HCS versus exposure time at $0 \%, 0.91 \%$ and $5.63 \% \mathrm{LAA} / 1 \mathrm{M} \mathrm{HCl}$ solution

Fig. 2 shows the optical image of HCS morphology before corrosion and after corrosion in $0 \% \mathrm{LAA} / 1 \mathrm{M} \mathrm{HCl}$ solution at $7200 \mathrm{~s}$ of exposure without applied potential. Fig. 3 shows the optical images of HCS after corrosion in $0.91 \%$ and $5.63 \% \mathrm{LAA} / 1 \mathrm{M} \mathrm{HCl}$. The differences in position of the plots agrees with the results in Table 4 . The open circuit corrosion potential plot at $0 \%$ LAA appears more electronegative than the plots at $0.91 \%$ and $5.63 \%$ LAA due to the electrochemical action of $\mathrm{Cl}^{-}$anions on HCS surface. This is proven from the stark contrast between the morphology in Fig. 2 b, and Fig. 3. Fig. 2 b shows a severely degraded morphology. The processes responsible for its occurrence have been explained under the weight loss sub-section. The corrosion potential plot at $0 \%$ LAA concentration initiated at $-0.384 \mathrm{~V}_{\mathrm{Ag} / \mathrm{AgCl}}(0 \mathrm{~s})$ and increased progressively before attaining quasi equilibrium state from $1000.01 \mathrm{~s}\left(-0.360 \mathrm{~V}_{\mathrm{Ag} / \mathrm{AgCl}}\right)$ to $7200 \mathrm{~s}$ at -0.356 $\mathrm{V}_{\mathrm{Ag} / \mathrm{AgCl}}$. The corrosion potential plot of $\mathrm{HCS}$ at $0.91 \%$ and $5.63 \%$ LAA concentration shifted in the positive direction due to the presence and inhibiting action of LAA compound which hindered the oxidation of HCS in the acid solution. $\mathrm{HCS}$ at $0.91 \%$ LAA attained quasi equilibrium state at $1000.0 \mathrm{~s}\left(-0.332 \mathrm{~V}_{\mathrm{Ag} / \mathrm{AgCl}}\right)$ to $7200 \mathrm{~s}$ at $-0.336 \mathrm{~V}_{\mathrm{Ag} / \mathrm{AgCl}}$. Increase in LAA concentration to $5.63 \%$ caused a further shift in corrosion potential to more positive values due to the presence of more LAA molecules to counteract the electrolytic diffusion and action of $\mathrm{Cl}^{-}$anions on $\mathrm{HCS}$ surface. The optical images in Fig. 3 confirms this assertion where the morphologies of HCS appears less deteriorated compared to the morphology at $0 \%$ LAA. The slight deterioration shown in Fig. 3 is due to the time dependent inhibition action of LAA compound as shown in Table 4 where the inhibition efficiency of LAA at $0.91 \%$ and $5.63 \%$ LAA concentration increased progressively with time from $12.43 \%$ and $51.19 \%$ at $24 \mathrm{~h}$ to $72.35 \%$ and $85.88 \%$ at $288 \mathrm{~h}$.
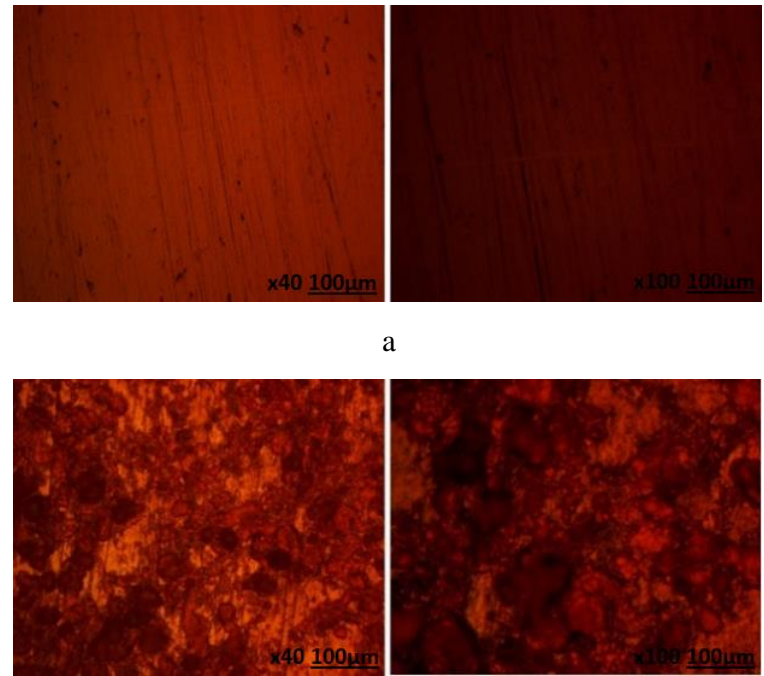

b

Fig. 2. Optical image of HCS (mag. X40 and x100): a-before corrosion; $\mathrm{b}$-after corrosion in $0.91 \% \mathrm{LAA} / 1 \mathrm{M} \mathrm{HCl}$ solution
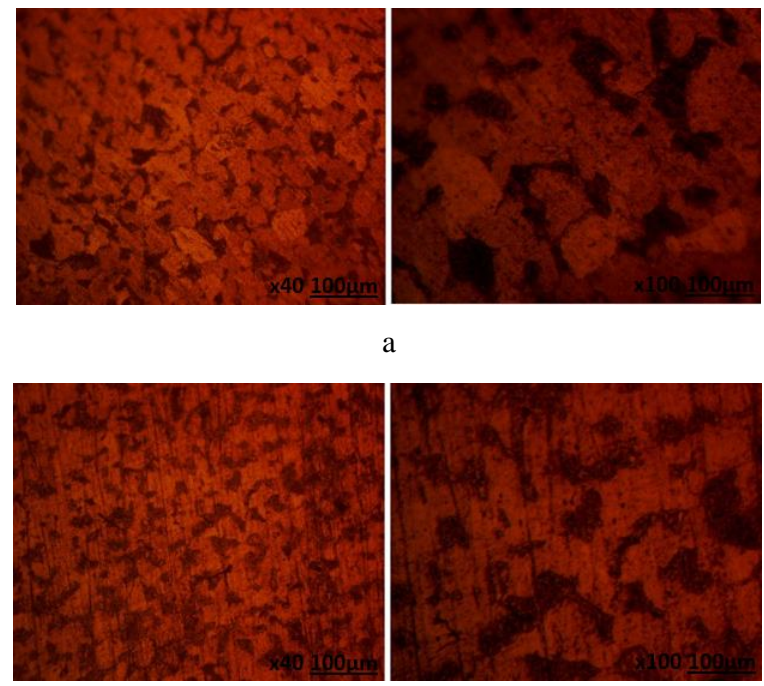

b

Fig. 3. Optical image of HCS (mag. X40 and x100): a-before corrosion; $\mathrm{b}$-after corrosion in $0.91 \% \mathrm{LAA} / 1 \mathrm{M} \mathrm{HCl}$ solution

\subsection{ATF-FTIR Spectroscopy analysis}

Functional groups present within LAA compound responsible for corrosion inhibition and adsorption reactions on HCS were exposed by ATF-FTIR spectroscopy and equated with ATR-FTIR Theoretical Table [16, 17]. Fig. 1 shows the spectra plots of $1 \mathrm{M} \mathrm{HCl} / \mathrm{LAA}$ solution before and 
after HCS corrosion. The transmittance of calculated wavenumbers of $1 \mathrm{M} \mathrm{HCl} / \mathrm{LAA}$ solution before corrosion at intervals between $500-3460 \mathrm{~cm}^{-1}$ increased visibly after corrosion due to concentration of LAA molecules on HCS surface. This observation shows limited adsorption of LAA molecules occurred due to physisorption adsorption, however judging from LAA inhibition efficiency data in Table 3, is assumed that LAA concentrated on HCS surface forming effective surface coverage of the steel which prevents further electrochemical reaction resulting in corrosion. Identified functional groups of alcohols, phenols, primary and secondary amines and amides, carboxylic acids, alkynes, aromatics, alkenes and alkanes consisting of bonds such as $\mathrm{O}-\mathrm{H}$ stretch, free hydroxyl, $\mathrm{H}-$ bonded, $\mathrm{N}-\mathrm{H}$ stretch, $-\mathrm{C}$ (triple bond) $\mathrm{C}-\mathrm{H}$ : $\mathrm{C}-\mathrm{H}$ stretch, $\mathrm{C}-\mathrm{H}$ stretch and $=\mathrm{C}-\mathrm{H}$ stretch bonds were responsible for the corrosion inhibition of HCS steel. The presence of $\mathrm{N}$ and $\mathrm{O}$ heteroatom within its molecular structure, the $\alpha$-amino groups $\left(\mathrm{NH}_{2}^{-}\right)$protonates to become positive $\alpha$-ammonium groups $\left(+\mathrm{NH}_{3}{ }^{-}\right)$in the acid solution and inhibits further corrosion of HCS through adsorption via the negatively charged chloride ions, resulting in the pi electrons and unshared electrons pairs forming a strong bond with vacant d-orbital of HCS surface [18]. In the presence of LAA compound, transition from active deterioration of HCS surface to the passive state was gradual due to the time dependent action of LAA adsorption on HCS.

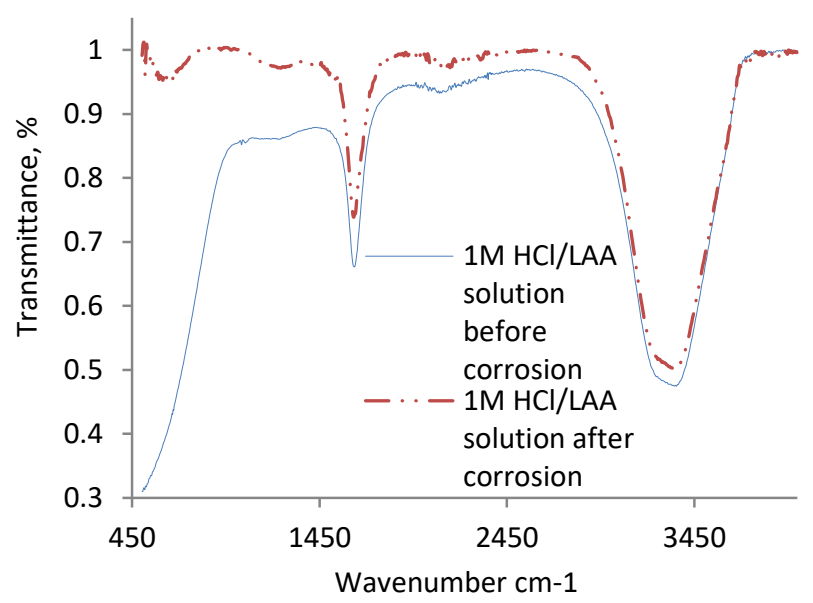

Fig. 4. ATF-FTIR spectra of $1 \mathrm{M} \mathrm{HCl/LAA}$ solution before and after HCS corrosion

\section{CONCLUSIONS}

L-alpha-aminoisocaproate effectively inhibited the corrosion of high carbon steel in $1 \mathrm{M} \mathrm{HCl}$ solution. The functional groups identified with ATF-FTIR spectral analysis adsorbed unto the steel through Van der Waals forces forming an effective molecular covering on the steel surface. The presence of heteroatoms within the protonated $\alpha$-amino groups in the acid solution progressively inhibits the electrochemical processes responsible for corrosion of the high carbon steel $[19,20]$. Open circuit potential plots from the acid solution with inhibitor concentrations were significantly more electropositive than the plot without inhibitor due to the protective film formed by the inhibitor molecules on the steel.

\section{Acknowledgements}

The author acknowledges Covenant University Ota, Ogun State, Nigeria for the sponsorship and provision of research facilities for this project.

\section{REFERENCES}

1. Singh, D.K., Kumar, S., Udayabhanu, G., John, R.P. 4(N,N-dimethylamino) Benzaldehyde Nicotinic Hydrazone as Corrosion Inhibitor for Mild Steel in $1 \mathrm{M} \mathrm{HCl}$ Solution: An Experimental and Theoretical Study Journal of Molecular Liquids 216 2016: pp. 738-746.

https://doi.org/10.1016/j.molliq.2016.02.012

2. Fiori-Bimbi, M.V., Alvarez, P.E., Vaca, H., Gervasi, C.A. Corrosion Inhibition of Mild Steel in $\mathrm{HCl}$ Solution by Pectin Corrosion Science 92 2015: pp. $192-199$

https://doi.org/10.1016/j.corsci.2014.12.002

3. Yadav, M., Behera, D., Sharma, U. Nontoxic Corrosion Inhibitors for N80 Steel in Hydrochloric Acid Arabian Journal of Chemistry 9 (2) 2016: pp. S1487-S1495. https://doi.org/10.1016/j.arabjc.2012.03.011

4. Zhao Zhao, J., Zhang, N., Qu, C., Wu, X., Zhang, J., Xiang Zhang, X. Cigarette Butts and Their Application in Corrosion Inhibition for N80 Steel at $90{ }^{\circ} \mathrm{C}$ in a Hydrochloric Acid Solution Industrial and Engineering Chemistry Research 49 2010: pp. 3986-3991. https://doi.org/10.1021/ie100168s

5. Renner, F.U., Stierle, A., $\quad$ Dosch, H., Kolb, D.M., Lee, T.L., Zegenhagen, J. Initial Corrosion Observed on the Atomic Scale Nature 439 2006: pp. 707-710. https://doi.org/10.1038/nature04465

6. Roy, P., Karfa, P., Adhikari, U., Sukul, D. Corrosion Inhibition of Mild Steel in Acidic Medium by Polyacrylamide Grafted Guar Gum with various Grafting Percentage: Effect of Intramolecular Synergism Corrosion Science 88 2014: pp. 246-253. https://doi.org/10.1016/j.corsci.2014.07.039

7. Obi-Egbedi, N.O., Obot, I.B. Inhibitive Properties, Thermodynamic and Quantum Chemical Studies of Alloxazine on Mild steel Corrosion in $\mathrm{H}_{2} \mathrm{SO}_{4}$ Corrosion Science 53 2011: pp. 263-275. https://doi.org/10.1016/j.corsci.2010.09.020

8. Shukla, S.K., Quraishi, M.A. The effects of Pharmaceutically Active Compound Doxycycline on the Corrosion of Mild steel in Hydrochloric Acid Solution Corrosion Science 52 2010: pp. 314-321. https://doi.org/10.1016/j.corsci.2009.09.017

9. Gece, G. Drugs: A Review of Promising Novel Corrosion Inhibitors Corrosion Science 53 2011: pp. 3873-3898. https://doi.org/10.1016/j.corsci.2011.08.006

10. Chevalier, M., Robert, F., Amusant, N., Traisnel, M., Roos, C., Lebrini, M. Enhanced Corrosion Resistance of Mild Steel in 1M Hydrochloric Acid Solution by Alkaloids Extract from Aniba Rosaeodora Plant: Electrochmical, Phytochemical and XPS Studies Electrochimica Acta 131 2014: pp. $96-105$. https://doi.org/10.1016/j.electacta.2013.12.023

11. Mazumder, M.A.J., Al-Muallem, H.A., Faiz, M., Ali, S.A. Design and Synthesis of a Novel Class of Inhibitors for Mild Steel Corrosion in Acidic and Carbon Dioxide- Saturated Saline Media Corrosion Science 87 2014: pp. $187-198$. https://doi.org/10.1016/j.corsci.2014.06.026 
12. Loto, R.T., Loto, C.A., Fedotova, T. Electrochemical Studies of Mild Steel Corrosion Inhibition in Sulfuric Acid Chloride by Aniline Research on Chemical Intermediates 40 (4) 2014: pp. $1501-1516$.

https://doi.org/10.1007/s11164-013-1055-x

13. Loto, R.T., Loto, C.A. Effect of $P$-Phenylediamine on the Corrosion of Austenitic Stainless-Steel Type 304 in Hydrochloric Acid International Journal of Electrochemical Science 7 (10) 2012: pp. 9423 -9440.

14. Loto, C.A., Loto, R.T., Popoola, A.P.I. Synergistic Effect of Tobacco and Kola Tree Extracts on the Corrosion Inhibition of Mild Steel in Acid Chloride International Journal of Electrochemical Science 6 (9) 2011: pp. 3830-3843.

15. Loto, R.T., Loto, C.A., Joseph, O., Olanrewaju, G. Adsorption and Corrosion Inhibition Properties of Thiocarbanilide on the Electrochemical Behavior of High Carbon Steel in Dilute Acid Solutions Results in Physics 6 2016: pp. $305-314$. https://doi.org/10.1016/j.rinp.2016.05.013

16. Table of Characteristic IR Absorptions.http://orgchem. colorado.edu/Spectroscopy/Specttutor/irchart.pdf (accessed 1 December 2017).
17. George, S. Infrared and Raman Characteristic Group Frequencies: Tables and Charts. John Wiley \& Sons, New York, p. 2004. https://doi.org/10.1002/jrs.1238

18. Kumar, P., Shetty, A.N. Inhibition Effect of Adsorption Layer of 1-Phenyl-4-(4-nitrophenyl) Thiosemicarbazide on the Corrosion of $18 \mathrm{Ni}$ 250-Grade Welded Maraging Steel in 1.0 M Hydrochloric Acid Medium Research on Chemical Intermediates $41(10)$ 2015: 7095-7113. https://doi.org/10.1007/s11164-014-1800-9

19. Behpour, M., Mohammadi, N. Use of Compounds Containing Heteroatoms as Electrochemical Corrosion Inhibitors for Copper in Hydrochloric Acid Journal Chemical Engineering Communications 200 (3) 2013: pp. $351-366$. https://doi.org/10.1080/00986445.2012.709473

20. Ahmad, M.E., Hytham, M.A., Alaa, E.A. Electrochemical and Analytical Study of the Corrosion Inhibitory behavior of Expired Pharmaceutical Compounds for C- Steel Corrosion International Journal of Electrochemical Science 10 2015: pp. $5112-5129$. 